\title{
Impaired Quality of Working Life in Inflammatory Bowel Disease Patients
}

\author{
Sara van Gennep ${ }^{1}$ (1) - Nanne K. H. de Boer ${ }^{1} \cdot$ Marieke E. Gielen $^{2} \cdot$ Svend T. Rietdijk $^{3} \cdot$ Krisztina B. Gecse $^{1}$. \\ Cyriel Y. Ponsioen ${ }^{1} \cdot$ Marjolijn Duijvestein $^{1}$ - Geert R. D'Haens ${ }^{1} \cdot$ Mark Löwenberg $^{1}$ • Angela G. E. M. de Boer ${ }^{4}$
}

Received: 17 July 2020 / Accepted: 28 September 2020 / Published online: 16 October 2020

(c) The Author(s) 2020

\begin{abstract}
Background Work-related aspects are important determinants of health for inflammatory bowel disease (IBD) patients. Aims We aimed to describe quality of working life (QWL) in IBD patients and to assess variables that are associated with QWL.

Methods Employed IBD patients of two tertiary and two secondary referral hospitals were included. QWL (range 0-100) was measured using the Quality of Working Life Questionnaire (QWLQ). Work productivity (WP), fatigue, and health-related quality of life (HRQL) were assessed using the Work Productivity and Activity Impairment questionnaire, Multidimensional Fatigue Inventory, and Short Inflammatory Bowel Disease Questionnaire, respectively. Active disease was defined as a score $>4$ for the patient-reported Harvey-Bradshaw index in Crohn's disease (CD) or Simple Clinical Colitis Activity Index in ulcerative colitis patients.

Results In total, 510 IBD patients were included (59\% female, 53\% CD, mean age 43 (SD 12) years). The mean QWLQ score was 78 (SD 11). The lowest subscore (54 (SD 26)) was observed for "problems due to the health situation": 63\% reported fatigue-related problems at work, $48 \%$ agreed being hampered at work, $46 \%$ had limited confidence in their body, and $48 \%$ felt insecure about the future due to their health situation. Intermediate/strong associations were found between QWL and fatigue $(r=-0.543, p<0.001)$, HRQL $(r=0.527, p<0.001)$, WP loss $(r=-0.453, p<0.001)$ and disease activity $(r=-0.331$, $p<0.001)$. Independent predictors of impaired QWL in hierarchical regression analyses were fatigue $(B=-0.204, p<0.001)$, WP loss $(B=-0.070, p<0.001)$, and impaired HRQL $(B=0.248, p=0.001)$.
\end{abstract}

Conclusions IBD-related problems at work negatively influence QWL. Fatigue, reduced HRQL, and WP loss were independent predictors of impaired QWL in IBD.

Keywords Inflammatory bowel disease · Quality of working life $\cdot$ Job satisfaction · Work performance $\cdot$ Fatigue $\cdot$ Quality of life

Sara van Gennep

s.vangennep@amsterdamumc.nl

1 Department of Gastroenterology and Hepatology, Amsterdam UMC, Amsterdam Gastroenterology and Metabolism Research Institute, University of Amsterdam, Meibergdreef 9, 1105 AZ Amsterdam, The Netherlands

2 Department of Gastroenterology and Hepatology, Amstelland Ziekenhuis, Amstelveen, The Netherlands

3 Department of Gastroenterology and Hepatology, OLVG, Amsterdam, The Netherlands

4 Department of Public and Occupational Health, Amsterdam UMC, Coronel Institute of Occupational Health, Amsterdam Public Health Research Institute, Amsterdam, The Netherlands

\section{Introduction}

Inflammatory bowel disease (IBD), including Crohn's disease (CD) and ulcerative colitis (UC), can lead to disabling symptoms, such as abdominal pain, bloody diarrhea, perianal disease, fatigue, anxiety, and depression. IBD is often diagnosed at an early age, a decisive period in which patients often begin their careers. It has been shown that IBD negatively influences work productivity and that it leads to higher unemployment and work disability rates compared to the healthy population $[1,2]$.

The working life of IBD patients has been studied in terms of work disability, work productivity losses, and the type of problems at work leading to work productivity loss. 
IBD disease activity plays a crucial role in the amount of work productivity loss [3]. In addition, a large proportion of IBD patients experience problems at work even while their disease is in remission $[4,5]$. The majority of patients relate these problems to fatigue $[4,5]$. Patients who struggle with IBD-related problems at work often experience increased stress levels and impaired quality of life which is why, in certain cases, accommodations to the workplace are needed in order to cope with their illness and (in)ability to work [4, 6]. Job satisfaction is an important factor influencing work performance, and poor work satisfaction might even lead to desertion from the organization $[7,8]$. Furthermore, work-related experiences including job satisfaction and occupational balance are considered some of the most important determinants of health for people with Crohn's disease (CD), yet they are not covered in existing patient-reported outcome (PRO) measurements used in CD [9].

The few studies that investigated the type of problems that IBD patients experience in more detail used different (mainly unstructured) strategies to assess work-related problems. For cancer survivors returning to work, the Quality of Working Life Questionnaire (QWLQ) has been developed to objectively measure quality of working life (QWL) [10]. Using the QWLQ, QWL is measured based on five subscales, including the meaning of work for the patient, their impression and perception of the work situation, the atmosphere in the working environment, understanding and recognition of their health situation in the organization, and problems at work due to the health situation. The primary aim of this study was to describe QWL using the QWLQ in an employed IBD cohort. Secondary, we aimed to assess variables that are associated with QWL in IBD.

\section{Methods}

\section{Study Design and Population}

This cross-sectional study was conducted as part of the WORK-IBD study, a prospective web-based study in employed IBD patients [5]. IBD patients between the age of 16 and 63 years old who attended the outpatient clinic at one of four academic and non-academic hospitals between May 1, 2017, and August 31, 2017, were invited to participate by letter. Patients who gave consent for participation and who were employed were eligible for inclusion. Employment was defined as: (1) working as an employee, (2) working as an independent entrepreneur (self-employed), or (3) partially disabled and partially working (receiving partial disability benefits).

\section{Data Collection and Outcome Measurements}

Surveys were completed online by use of the cloud-based Castor Electronic Data Capture (EDC) platform or by paper questionnaire according to patient preference [11]. For this cross-sectional study, data of the baseline questionnaire were analyzed. Questionnaires included the QWLQ to measure QWL [10]. This questionnaire was developed to measure QWL in cancer survivors returning to work and was validated to be used in clinical and occupational healthcare and research settings for this patient population. Other questionnaires included the Work Productivity and Activity Impairment (WPAI) questionnaire [12], the Multidimensional Fatigue Inventory (MFI) [13], and the Short Inflammatory Bowel Disease Questionnaire (SIBDQ) [14] to measure work productivity loss, fatigue, and IBD-specific health-related quality of life (HRQL), respectively. To determine clinical disease activity, patient-reported simple clinical colitis activity index (p-SCCAI) for UC patients and patient-reported Harvey-Bradshaw Index (p-HBI) for CD patients were used $[15,16]$.

The QWLQ consists of 23 items and is divided into five subscales: (1) meaning of work, (2) impression/perception of the work situation, (3) atmosphere in the working environment, (4) understanding and recognition in the organization, and (5) problems due to the health situation [10]. QWLQ responses were scored on a 6-point scale [totally disagree (1) to totally agree (6)] and higher scores indicated better QWL [17]. Total QWLQ score (0-100) and the five subscale scores $(0-100)$ were calculated when at least $50 \%$ of the items were answered [17]. When the "not applicable" category was filled in the case of self-employed patients, this was scored as missing. Work productivity loss was measured with the Work Productivity and Activity Impairment questionnaire and quantified using the percentage absenteeism (calculated based on the percentage of hours missed due to IBD during the past week), presenteeism (based on a 0-10 score of work impairment due to IBD while working), and overall work productivity loss due to IBD in the past week (calculated using the formula: absenteeism $+(1-$ absenteeism) $\times$ presenteeism) [12]. The 20-item Multidimensional Fatigue Inventory (total score 20-100) is divided into five subscores: general fatigue, physical fatigue, reduced activity, reduced motivation, and mental fatigue [13]. A higher score indicates more severe fatigue. The Short Inflammatory Bowel disease Questionnaire consists of 10-items, and the total score ranges from 10 to 70 (best health) [14]. 


\section{Statistical Analysis}

Continuous data were depicted as mean with standard deviation (SD) or median with interquartile range (IQR) according to distribution, categorical data as frequencies with percentages. Categorical variables were compared using Chi-square tests or Fisher's exact tests, and continuous data were compared using independent samples $T$ tests or Mann-Whitney U tests depending on distribution. To analyze potential associations among QWL and other variables (including patient-related, IBD-related, and workrelated variables) or patient-reported outcomes (including fatigue, HRQL, and work productivity loss), Pearson's correlations were performed. A correlation coefficient $(r)$ value that ranged between 0.5 and 1.0 or -0.5 and -1.0 was considered as a strong association. A low strength of association was assumed for values between 0.1 to 0.3 and -0.1 to -0.3 and intermediate strength for values between 0.3 to 0.5 and -0.3 to -0.5 , respectively. Hierarchical regression analyses were used to assess independent predictors of QWL in IBD patients. In the first step, all significantly $(p<0.05)$ associated patient- and diseaserelated variables were included; in the second step, all significantly correlated treatment- and work-related variables were included; and in the third step, other patient-reported outcomes that were found to be significantly associated with QWL were added. Outcomes were presented using unstandardized $(B)$ and standardized $(\beta)$ coefficients and associated $\mathrm{p}$ values. The amount of variance in QWLQ score explained by the model was presented in terms of the $\mathrm{R}$ squared $\left(R^{2}\right)$ value. A $p$ value $<0.05$ was considered statistically significant. All analyses were performed with IBM $^{\circledR}$ SPSS $^{\circledR}$ Statistics version 26.

\section{Results}

\section{Patient Characteristics}

In total, 1590 (potentially employed) IBD patients between 15 and 63 years of age were identified out of which 768 (48\%) responded to the initial invitation. From these 767 patients, 563 (73\%) were eligible, 86 patients declined, and 119 were not eligible. Baseline questionnaires were completed by $536(95 \%)$ patients, after which another 26 patients had to be excluded for complete work disability. A detailed flow diagram of included and excluded patients was published in the previous work [5]. Characteristics of 510 included patients are summarized in Table 1. Patients had a mean age of 43 (SD 12) years, a median disease duration of 11 (IQR 5-20) years, and 59\% were female. Forty-eight percent of the patients were diagnosed with $\mathrm{UC}, 52 \%$ had $\mathrm{CD}$, and $21 \%$ of the patients reported clinical
Table 1 Patient demographics

\begin{tabular}{|c|c|}
\hline & $\begin{array}{l}\text { Total } \\
n=510\end{array}$ \\
\hline Age (years) & $43 \pm 12$ \\
\hline Female gender & $299(59 \%)$ \\
\hline Low level of education ${ }^{a}$ & $87(17 \%)$ \\
\hline Active smoking & $56(11 \%)$ \\
\hline Working $\geq 36 \mathrm{~h}$ per week & $242(47 \%)$ \\
\hline Managerial position & $116(23 \%)$ \\
\hline Self-employed & $85(17 \%)$ \\
\hline Breadwinner position & $270(53 \%)$ \\
\hline Blue-collar work & $25(5 \%)$ \\
\hline Disease duration (years) & $11(5-20)$ \\
\hline Ulcerative colitis & $242(48 \%)$ \\
\hline Proctitis (E1) & $39(16 \%)$ \\
\hline Left sided (E2) & $82(34 \%)$ \\
\hline Extensive (E3) & $113(47 \%)$ \\
\hline Crohn's disease & $268(53 \%)$ \\
\hline Ileal (L1) & $83(31 \%)$ \\
\hline Colonic (L2) & $67(25 \%)$ \\
\hline Ileocolic (L3) & $113(42 \%)$ \\
\hline Upper GI (+ L4) & $19(7 \%)$ \\
\hline Stricturing or penetrating (B2 or B3) & $103(38 \%)$ \\
\hline Clinical disease activity ${ }^{\mathrm{b}}$ & $107(21 \%)$ \\
\hline Active perianal disease ${ }^{c}$ & $28(10 \%)$ \\
\hline Active arthralgia & $163(32 \%)$ \\
\hline Failed $\geq 1$ biological & $166(33 \%)$ \\
\hline Corticosteroid use & $28(6 \%)$ \\
\hline Mesalamine use & $184(36 \%)$ \\
\hline Immunomodulator use $^{\mathrm{d}}$ & $154(30 \%)$ \\
\hline Anti-TNF use & $123(24 \%)$ \\
\hline Vedolizumab use & $26(5 \%)$ \\
\hline Ustekinumab use & $12(2 \%)$ \\
\hline Stoma & $28(6 \%)$ \\
\hline Ileal pouch-anal anastomosis & $14(3 \%)$ \\
\hline
\end{tabular}

${ }^{a}$ Low level of education includes elementary school (no secondary or higher education); anti-TNF, anti-tumor necrosis factor; ' ${ }^{\mathrm{b}}$ Patientreported Simple Clinical Colitis Activity Index or patient-reported Harvey-Bradshaw index $>4$; ' Only measured in Crohn's disease patients; ${ }^{\mathrm{d}}$ Immunomodulatory included thiopurines or methotrexate

disease activity at the time of completing the questionnaires. Almost half of the patients $(47 \%)$ reported an employment contract of at least $36 \mathrm{~h}$ per week and $17 \%$ were self-employed.

\section{Quality of Working Life}

Mean (SD) scores of the QWLQ subscales and QWLQ total score are depicted in Fig. 1. The mean QWLQ score was 78 (SD 11). In general, high mean scores were found 
for the subscales importance of work [mean 84 (SD 15)], impression/perception of the work situation [mean 82 (SD 13)], atmosphere in the working environment [mean 81 (SD 14)], and understanding and recognition in the organization [mean 76 (SD 17)]. For these subscales, more than $70 \%$ of patients scored 5 or 6 on the 6-point scale for all individual items [totally disagree (1) to totally agree (6)], indicating substantial agreement with statements such as "working provides structure in my life," "I feel a positive atmosphere in my work environment," "my manager understands my health situation," and "employees with health complaints are treated well within my organization." The item "I am satisfied with my salary" was the only statement that less than $70 \%$ of patients substantially agreed to (score of 5 or 6 ). The lowest mean score of 54 (SD 26) was found for the subscale "problems due to the health situation." In the total IBD cohort, 63\% (317/507) of patients reported having problems at work that were associated with fatigue and low energy, $48 \%(145 / 507)$ agreed being hampered at work due to their health situation, $46 \%$ (231/507) had limited confidence in their body, and $48 \%$ (245/507) of patients felt insecure about the future due to their health situation (Table 2).

\section{Variables Associated with Quality of Working Life (QWL)}

A strong positive association was found between QWL and HRQL $(r=0.527, p<0.001$, Fig. 2a). Significant positive associations of low strength were detected between QWL and level of education $(r=0.124, p=0.005)$ and the number of working hours (contract hours) per week ( $r=0.157$, $p<0.001)$. A strong negative association was observed between QWL and fatigue ( $-0.543, p<0.001$, Fig. $2 b)$. Associations of intermediate strength were found amid QWL and the percentage of overall work productivity loss (absenteeism + presenteeism) in the past week related to IBD ( $r=-0.453, p<0.001$, Fig. 2c) and between QWL and clinical disease activity $(r=-0.331, p<0.001)$. Arthralgia $(r=-0.170, p<0.001)$ and corticosteroid use $(r=-0.105$, $p=0.018$ ) were significantly associated with QWL, yet the association was of low strength. Differences in mean (SD) QWLQ scores according to the presence or absence of the variables clinical disease activity, arthralgia, and corticosteroid are shown in Fig. 3. Other factors, including type of diagnosis (CD versus $\mathrm{UC}, r=-0.049, p=0.270)$, gender $(-0.003, p=0.949)$, age $(r=0.058, p=0.196)$, active perianal disease $(r=-0.003, p=0.966)$, prior surgery $(-0.006$, $p=0.888)$, and disease duration $(r=0.022, p=0.618)$, were not significantly correlated with QWL.

\section{Predictors of Impaired Quality of Working Life}

Multivariable hierarchical regression analyses (Table 3) revealed that work productivity loss $(B=-0.070, p<0.001)$ and fatigue $(B=-0.204, p<0.001)$ were independent negative predictors of QWL. HRQL was found to be an independent positive predictor of QWL $(B=0.248, p=0.001)$. The model comprising the factors such as clinical disease activity, active arthralgia, oral corticosteroid use, amount of contract hours per week, level of education, percentage work productivity loss, fatigue, and HRQL explained the proportion of variance in QWL by $37 \%\left(R^{2}=0.369\right)$.

\section{Discussion}

We here explored QWL in IBD patients using the QWLQ that was initially developed to objectively measure QWL in cancer survivors returning to work [10]. Since other available QWL questionnaires were developed for healthy employees and did not include effects of an existing disease, the QWLQ seems the best available QWL questionnaire to be used in IBD to date [18]. Important items in the QWLQ that were formulated based on focus groups with cancer survivors were: (1) problems with fatigue that negatively influence work, (2) poor confidence in their own body, and
Fig. 1 Quality of working life in inflammatory bowel disease patients. Mean (SD) total Quality of Working Life Questionnaire (QWLQ) score and subscores of the total IBD cohort

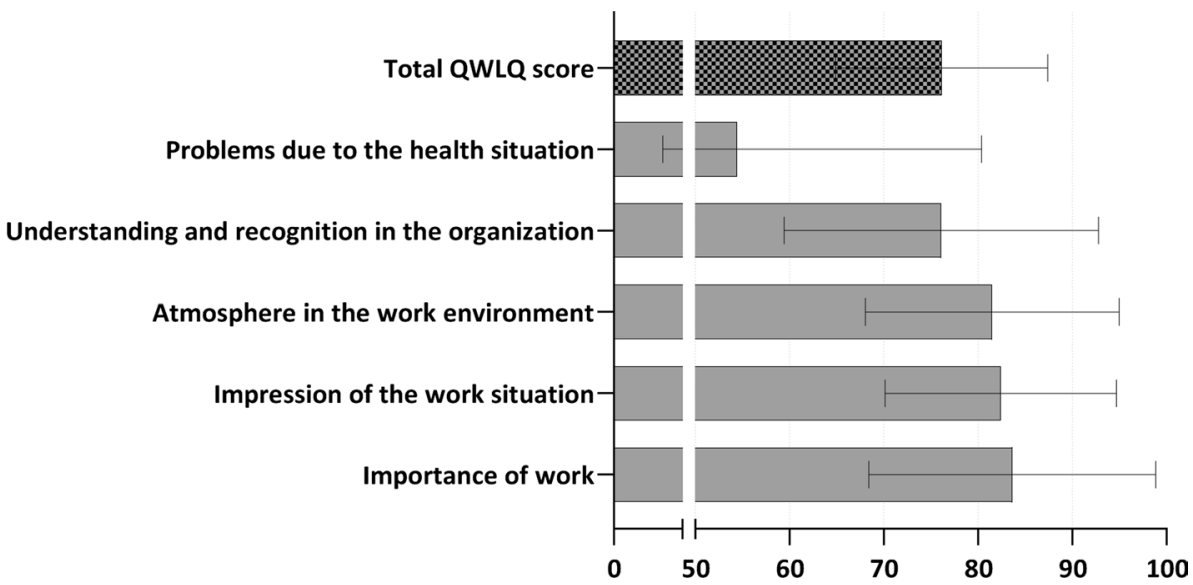


Table 2 Quality of Working Life Questionnaire (QWLQ) scores per item

\begin{tabular}{|c|c|c|c|c|c|c|}
\hline & & $\begin{array}{l}\text { Substantial } \\
\text { disagreement } \\
N(\%)\end{array}$ & $\begin{array}{l}\text { A little } \\
\text { disagreement } \\
N(\%)\end{array}$ & $\begin{array}{l}\text { A little } \\
\text { agreement } \\
N(\%)\end{array}$ & $\begin{array}{l}\text { Substantial } \\
\text { agreement } N \\
(\%)\end{array}$ & $\begin{array}{l}\text { Total answers } \\
N\end{array}$ \\
\hline \multicolumn{7}{|c|}{ Meaning of work } \\
\hline 1 & Work provides structure in life & $12(2.4)$ & $4(0.8)$ & $60(11.9)$ & $430(85.0)$ & 506 \\
\hline 2 & Work is important/valuable & $7(1.4)$ & $6(1.2)$ & $23(4.5)$ & $470(92.9)$ & 506 \\
\hline 3 & Work provides a goal in life & $26(5.1)$ & $17(3.3)$ & $90(17.6)$ & 374 (73.9) & 506 \\
\hline 4 & My job is important & $8(1.6)$ & $8(1.6)$ & $60(11.9)$ & $430(85.0)$ & 506 \\
\hline \multicolumn{7}{|c|}{ Perception of work situation } \\
\hline 5 & I am doing my job well & $2(0.4)$ & $3(0.6)$ & $29(5.7)$ & $472(93.3)$ & 506 \\
\hline 6 & Feeling confident at work & $5(1.0)$ & $16(3.2)$ & $69(13.6)$ & $416(82.2)$ & 506 \\
\hline 7 & Feeling competent for job & $3(0.6)$ & $8(1.6)$ & $28(5.5)$ & $467(92.3)$ & 506 \\
\hline 8 & Feeling in charge while working & $17(3.4)$ & $12(2.4)$ & $90(17.8)$ & $388(76.5)$ & 507 \\
\hline 9 & Feeling powerless at work & $430(84.8)$ & $21(4.1)$ & $41(8.1)$ & $15(3.0)$ & 507 \\
\hline \multicolumn{7}{|c|}{ Atmosphere in working environment } \\
\hline & Positive atmosphere in work environment & $19(3.7)$ & $32(6.3)$ & $69(13.6)$ & $387(76.3)$ & 507 \\
\hline 11 & Being taken serious by people in work environment & $9(1.8)$ & $12(2.4)$ & $43(8.5)$ & $443(87.4)$ & 507 \\
\hline 12 & Satisfied with job & $22(4.3)$ & $25(4.9)$ & $63(12.5)$ & $396(78.3)$ & 506 \\
\hline 13 & Good relationships with colleagues & $9(1.9)$ & $8(1.7)$ & $34(7.1)$ & $435(91.0)$ & 478 \\
\hline 14 & Feeling valuable to colleagues & $5(1.0)$ & $7(1.5)$ & $46(9.6)$ & $422(87.9)$ & 480 \\
\hline \multicolumn{7}{|c|}{ Understanding/recognition in organization } \\
\hline & Manager understands health situation & $17(4.8)$ & $15(4.2)$ & $46(13.0)$ & $277(78.0)$ & 355 \\
\hline 16 & Good relationship with manager & $14(3.2)$ & $15(2.4)$ & $47(10.8)$ & $359(82.5)$ & 435 \\
\hline 17 & $\begin{array}{l}\text { Employees with health complaints are treated well within } \\
\text { organization }\end{array}$ & $26(6.3)$ & $25(6.1)$ & $61(14.8)$ & $299(72.7)$ & 411 \\
\hline 18 & Satisfied with fringe benefits & $29(7.6)$ & $10(2.6)$ & $47(12.3)$ & $296(77.5)$ & 382 \\
\hline 19 & Satisfied with salary & $59(11.6)$ & $30(5.9)$ & $118(23.3)$ & $300(59.2)$ & 507 \\
\hline \multicolumn{7}{|c|}{ Problems due to health situation } \\
\hline 20 & $\begin{array}{l}\text { Problems at work with fatigue and energy due to health } \\
\text { situation }\end{array}$ & $167(32.9)$ & $23(4.5)$ & $151(29.8)$ & $166(32.7)$ & 507 \\
\hline 21 & Hampered at work due to health situation & $220(43.4)$ & $42(8.3)$ & $142(28.0)$ & $103(20.3)$ & 507 \\
\hline 22 & Limited confidence in body due to health situation & $229(45.2)$ & $47(9.3)$ & $136(26.8)$ & $95(18.7)$ & 507 \\
\hline 23 & Insecure about future due to health situation & $218(43.0)$ & $44(8.7)$ & $127(25.0)$ & $118(23.3)$ & 507 \\
\hline
\end{tabular}
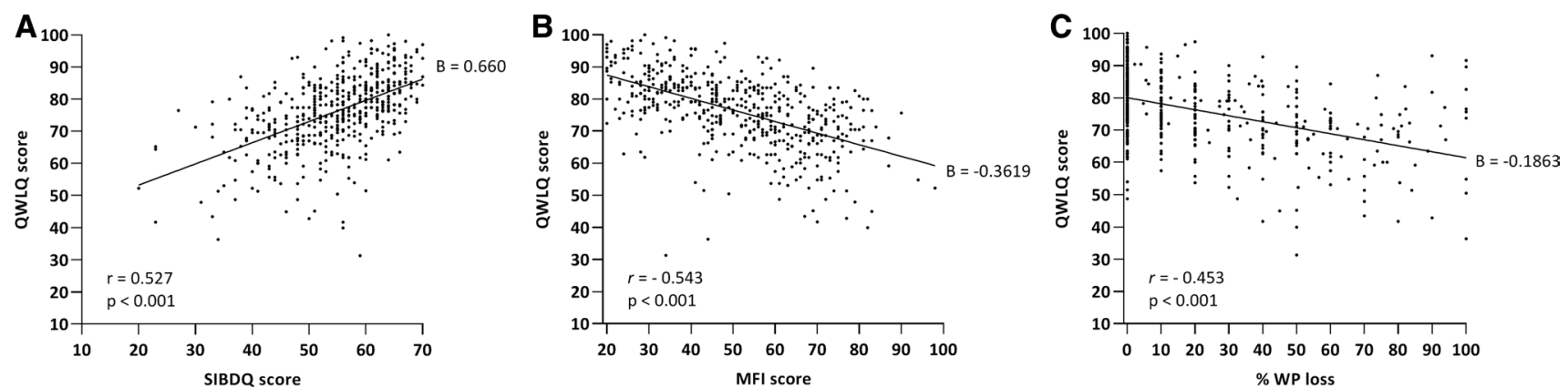

Fig. 2 Associations between quality of working life and fatigue, IBDspecific health-related quality of life, and work productivity loss. a Association between quality of working life (quality of working life questionnaire (QWLQ) score) and health-related quality of life (short inflammatory bowel disease questionnaire (SIBDQ) score). b Association between quality of working life (QWLQ score) and fatigue
(Multidimensional Fatigue Inventory (MFI) score). c Association between quality of working life (QWLQ score) and overall work productivity loss due to IBD in the past week (percentage of work productivity (WP) loss). $B$ unstandardized regression coefficient, $r$ Pearson's correlation coefficient 


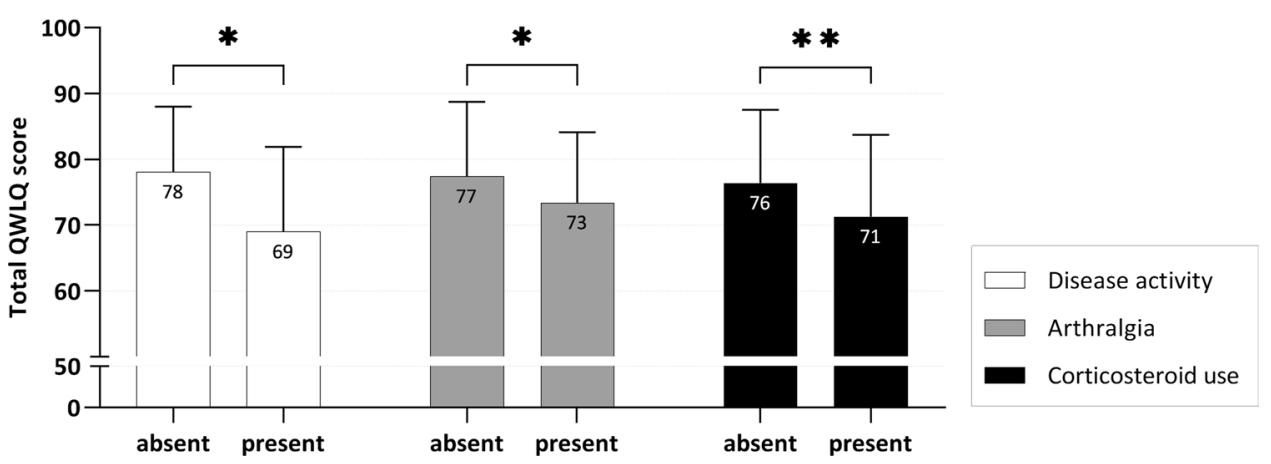

Fig. 3 Quality of working life according to the presence of disease activity, arthralgia and corticosteroid use. Mean (SD) total Quality of Working Life Questionnaire (QWLQ) scores compared between

Table 3 Predictors of quality of working life (hierarchical regression analysis)

\begin{tabular}{|c|c|c|c|c|}
\hline & $B$ & $\beta$ & $R^{2}$ & $p$ value \\
\hline Step 1 & & & 0.113 & \\
\hline Clinical disease activity ${ }^{\mathrm{a}}$ & -8.487 & -0.308 & & 0.000 \\
\hline Active arthralgia & -1.659 & -0.069 & & 0.122 \\
\hline Step 2 & & & 0.143 & \\
\hline Clinical disease activity ${ }^{\mathrm{a}}$ & -8.024 & -0.291 & & 0.000 \\
\hline Active arthralgia & -1.316 & -0.055 & & 0.216 \\
\hline Oral corticosteroid use & -4.633 & -0.094 & & 0.024 \\
\hline Contract hours per week & 0.111 & 0.109 & & 0.010 \\
\hline Level of education ${ }^{\mathrm{b}}$ & 1.214 & 0.083 & & 0.051 \\
\hline Step 3 & & & 0.369 & \\
\hline Clinical disease activity ${ }^{\mathrm{a}}$ & -0.991 & -0.036 & & 0.427 \\
\hline Active arthralgia & 1.438 & 0.060 & & 0.128 \\
\hline Oral corticosteroid use & -3.062 & -0.062 & & 0.085 \\
\hline Contract hours per week & 0.040 & 0.039 & & 0.293 \\
\hline Level of education & 0.946 & 0.064 & & 0.078 \\
\hline Work productivity loss (\%) & -0.070 & -0.169 & & 0.000 \\
\hline Fatigue (total MFI score) & -0.204 & -0.307 & & 0.000 \\
\hline HRQL (total SIBDQ score) & 0.248 & 0.197 & & 0.001 \\
\hline
\end{tabular}

${ }^{a}$ Defined as a patient-reported Simple Clinical Colitis Activity Index or patient-reported Harvey-Bradshaw index score $>4$; ' ${ }^{\mathrm{b}}$ Unstandardized regression coefficient, $\beta$ standardized regression coefficient, $M F I$ Multidimensional Fatigue Inventory, $H R Q L$ health-related quality of life, $R^{2}$ the proportion of the variance in Quality of Working Life Questionnaire (QWLQ) score explained by the model, SIBDQ Short Inflammatory Bowel Disease Questionnaire

(3) feeling insecure about the future, items that are known problems reported by patients with IBD [5, 19, 20]. The QWLQ measures QWL based on five concepts, including the meaning of work for the patient, the perception of the work situation, the atmosphere in the working environment, understanding and recognition of the health situation in the organization, and problems at work due to the the absence and presence of clinical disease activity (p-HBI or p-SCCAI > 4), arthralgia and corticosteroid use at the time of completing the questionnaire. ${ }^{*} p<0.0001 ; * * p=0.018$

health situation. It was previously shown that CD patients consider work-related aspects, such as job satisfaction and occupational balance, among the most important determinants of health. Still, this factor is not covered in existing PRO measurements used in IBD [9]. In addition, job satisfaction is known to influence work performance, and poor satisfaction might even lead to desertion from the organization [7, 8]. A mean QWLQ score of 78 (SD 11) was found in our IBD cohort (scale $0-100$ ), which is comparable to the mean QWLQ score of 75 (SD 12) that was observed in cancer survivors returning to work [21]. The relatively high QWLQ score that we found is in line with results of a French nationwide study that revealed job satisfaction in $76 \%$ of IBD patients, despite the fact that $50 \%$ of them stated that working with IBD was a problem [22]. As expected, IBD patients scored the lowest on the subscale "problems due to the health situation" (mean 54, SD 26). This subscore was slightly higher compared to cancer survivors who had returned to work (mean 49, SD 27) [21].

Disease-related variables that were associated with impaired QWL in IBD patients included clinical disease activity, presence of arthralgia, and systemic corticosteroid use. However, in multivariable hierarchical regression analyses only PROs that measured fatigue, HRQL, and work productivity loss were found to be independent predictors of QWL. These results are in line with previous work from our group in which we revealed that, despite disease activity, fatigue is the most relevant factor accounting for work productivity loss in IBD [5]. In addition, arthralgia complaints were significantly correlated with the presence of severe fatigue [5]. Fatigue is a frequently mentioned symptom expressed by IBD patients at the outpatient clinic. It affects approximately $50 \%$ of patients in clinical remission and $>80 \%$ of patients with active disease and significantly impairs daily life of IBD patients [23]. Therefore, awareness of this association between fatigue and impaired QWL is of great importance. However, the pathophysiology of fatigue 
is complex and multidimensional. Healthcare professionals who treat IBD patients should address potential causes of fatigue, by timely optimization and upscaling of therapies in patients with active inflammation, recognizing potential side effects and comorbidities, evaluating nutrient deficiencies and addressing psychological comorbidities and sleep disturbances [23]. Patients might benefit from psychological interventions, physical activity, or even pharmacological of microbiota-directed interventions [23].

In cancer survivors returning to work, QWL was impaired in patients without a managerial position, in patients that worked less than $100 \%$ of their contract hours (work productivity loss), in patients with a lower gross income $(<€ 1000)$ and in patients with high physically demanding work [21]. In contrast, we did not find significant associations with regard to QWL considering the variables managerial position and blue-collar (physical demanding) work. Yet, in line with results obtained in cancer survivors, we found associations of low strength between impaired QWL and lower education level (which may be associated with a lower income) and between impaired QWL and a lower number of working hours per week. Although these factors were not independently predictive for impaired QWL after associations were corrected for fatigue, HRQL, and work productivity loss.

This is the first study in which QWL was explored in IBD patients using the QWLQ, an objective and validated PRO. In addition, we used validated PROs to measure fatigue, IBD-specific HRQL, and work productivity loss. For this study, a relatively large number of IBD patients were included from secondary and tertiary referral hospitals. This has led to a variety of IBD patients with different disease severity stages and treatment regimens, which has contributed to external validity. However, certain limitations need to be addressed. First, while the QWLQ is a validated PRO tool to measure QWL in cancer survivors returning to work, it has not been validated to measure QWL in the IBD population. It might be that certain questions in the QWLQ are not that meaningful for IBD patients when compared to cancer survivors. Lack of IBD-specific questions in the QWLQ could have led to the absence of a significant association between disease activity and impaired QWL in our multivariable analyses after introducing other patient-reported outcomes. On the contrary, the QWLQ only contains generic questions without disease-related symptoms and was developed using a healthy control group. Nonetheless, the comparable QWLQ scores between IBD patients and cancer survivors and the (univariable) association of QWL with disease activity and fatigue suggest that the QWLQ is useful to measure QWL in IBD patients. Although validated PROs were used to measure fatigue, disease-specific HRQL, and work productivity, it was recently shown that the majority of PROs appear to have low-quality content validity and lacked patient involvement in the development and evaluation [24]. Other limitations include the cross-sectional study design and potentially induced selection bias due to patients who declined participation. In addition, the response rate of patients that participated seemed low (510 eligible participants out of 1590 potentially eligible IBD patients). However, the actual response rate might be higher due to the fact that a selection of the 1590 invited IBD patients was not employed and therefore was not eligible to participate in the first place. Lastly, IBD disease activity was measured using a PRO tool, while no biochemical or endoscopic parameters were used. Self-reported disease-activity sometimes correlates poorly with endoscopic disease activity, especially in CD patients [25, 26], and this might therefore be an indicator of perceived burden of disease.

This cross-sectional study demonstrates that diseaserelated variables that indicate the presence of active disease (such as clinical disease activity, arthralgia and corticosteroid use) are associated with impaired QWL in IBD patients, yet these variables are not independently predictive for QWL. However, fatigue, impaired IBD-specific HRQL, and work productivity loss were revealed to be independent predictors of impaired QWL. This study will hopefully increase the awareness regarding the presence of IBDrelated problems at work that negatively impact QWL, even in the absence of disease activity. Based on this knowledge, it is important to identify patients with increased risk of impaired QWL at an early stage. These patients might benefit from support (for example, by occupational health physicians) to increase QWL and in certain cases accommodations to the workplace are needed in order to cope with their illness and (in)ability to work. This in turn might lead to less work productivity loss, increased overall quality of life, and lower work disability and unemployment rates in IBD patients. QWL might be considered a new and important PRO in future studies in IBD. The QWLQ is an interesting tool that can be used as a basis for future development of an IBD-specific QWL questionnaire.

Acknowledgments We would like to thank all the patients that participated in this study.

Funding This work was supported by an unrestricted grant by Dr. Falk Pharma Benelux B.V (Grant Number FALK-BNL-2016-029).

\section{Compliance with Ethical Standards}

Conflict of interest SG: none; NB: has served as a speaker for AbbVie, Takeda, and MSD. He has served as consultant and principal investigator for Takeda and TEVA Pharma B.V. He has received a (unrestricted) research grant from Dr. Falk, TEVA Pharma B.V, MLDS, and Takeda; MG: none; SR: none; KG: has received consultancy fees and/or speaker's honoraria from AbbVie, Celltrion, Ferring, Immunic Therapeutics, Janssen, Pfizer, Roche, Sandoz, Samsung Bioepis, Takeda, and Tillotts; CP: has served as a speaker for Takeda, Tillotts, and Roche. He has served as advisor for Takeda, Pliant, and Shire. He 
has received grant support from Takeda. MD: reports advisory fees from Echo Pharma and Robarts Clinical Trials, Inc., speaker fees from Janssen, Merck \& Co., Inc., Pfizer, Takeda and Tillotts Pharma, and nonfinancial support from Dr. Falk. GD: has served as advisor for Abbvie, Ablynx, Amakem, AM Pharma, Avaxia, Biogen, Bristol Meiers Squibb, Boerhinger Ingelheim, Celgene, Celltrion, Cosmo, Covidien, Ferring, DrFalk Pharma, Engene, Galapagos, Gilead, Glaxo Smith Kline, Hospira, Immunic, Johnson and Johnson, Lycera, Medimetrics, Millenium/Takeda, Mitsubishi Pharma, Merck Sharp Dome, Mundipharma, Novonordisk, Pfizer, Prometheus laboratories/Nestle, Protagonist, Receptos, Robarts Clinical Trials, Salix, Sandoz, Setpoint, Shire, Teva, Tigenix, Tillotts, Topivert, Versant and Vifor and received speaker fees from Abbvie, Ferring, Johnson and Johnson, Merck Sharp \& Dohme, Mundipharma, Norgine, Pfizer, Shire, Millenium/Takeda, Tillotts and Vifor.; ML: served as speaker and/or principal investigator for Abbvie, Celgene, Covidien, Dr. Falk, Ferring Pharmaceuticals, Gilead, GlaxoSmithKline, Janssen-Cilag, Merck Sharp \& Dohme, Pfizer, Protagonist therapeutics, Receptos, Takeda, Tillotts, Tramedico and has received research grants from AbbVie, Merck Sharp \& Dohme, Achmea healthcare and ZonMW.; AB: none.

Ethical approval For this study a waiver was granted by the Medical Ethics Review Committee of the Academic Medical Center. The Medical Research Involving Human Subjects Act (WMO) did not apply to this study (W17_190).

Open Access This article is licensed under a Creative Commons Attribution-NonCommercial 4.0 International License, which permits any non-commercial use, sharing, adaptation, distribution and reproduction in any medium or format, as long as you give appropriate credit to the original author(s) and the source, provide a link to the Creative Commons licence, and indicate if changes were made. The images or other third party material in this article are included in the article's Creative Commons licence, unless indicated otherwise in a credit line to the material. If material is not included in the article's Creative Commons licence and your intended use is not permitted by statutory regulation or exceeds the permitted use, you will need to obtain permission directly from the copyright holder. To view a copy of this licence, visit http://creativecommons.org/licenses/by-nc/4.0/.

\section{References}

1. Spekhorst LM, Oldenburg B, van Bodegraven AA, et al. Prevalence of- and risk factors for work disability in Dutch patients with inflammatory bowel disease. World $J$ Gastroenterol. 2017;23:8182-8192.

2. Büsch K, da Silva SA, Holton M, Rabacow FM, Khalili H, Ludvigsson JF. Sick leave and disability pension in inflammatory bowel disease: a systematic review. J Crohns Colitis. 2014;8:1362-1377.

3. Williet N, Sarter H, Gower-Rousseau C, et al. Patient-reported outcomes in a French nationwide survey of inflammatory bowel disease patients. J Crohns Colitis. 2017;11:165-174.

4. Zand A, van Deen WK, Inserra EK, et al. Presenteeism in inflammatory bowel diseases: a hidden problem with significant economic impact. Inflamm Bowel Dis. 2015;21:1623-1630.

5. van Gennep S, Evers SW, Rietdijk ST, et al. High disease burden drives indirect costs in employed inflammatory bowel disease patients: the WORK-IBD study. Inflamm Bowel Dis. 2020; https ://doi.org/10.1093/ibd/izaa082.

6. Paulides E, Gearry RB, de Boer NKH, Mulder CJJ, Bernstein CN, McCombie AM. Accommodations and adaptations to overcome workplace disability in inflammatory bowel disease patients: a systematic review. Inflamm Intest Dis. 2019;3:138-144.

7. Mosadeghrad AM. Quality of working life: an antecedent to employee turnover intention. Int J Heal Policy Manag. 2013;1:43-50.

8. Arnold AE, Coffeng JK, Boot CRL, et al. The relationship between job satisfaction and productivity-related costs: a longitudinal analysis. J Occup Environ Med. 2016;58:874-879.

9. Dür M, Sadloňová M, Haider S, et al. Health determining concepts important to people with Crohn's disease and their coverage by patient-reported outcomes of health and wellbeing. J Crohn's Colitis. 2014;8:45-55.

10. de Jong M, Tamminga SJ, van Es RJJ, Frings-Dresen MHW, de Boer AGEM. The quality of working life questionnaire for cancer survivors (QWLQ-CS): factorial structure, internal consistency, construct validity and reproducibility. BMC Cancer. 2018;18:66.

11. Ciwit BV. Castor electronic data capture. Amsterdam: Ciwit B.V; 2018.

12. Reilly MC, Zbrozek AS, Dukes EM. The validity and reproducibility of a work productivity and activity impairment instrument. Pharmacoeconomics. 1993;4:353-365.

13. Smets EM, Garssen B, Bonke B, De Haes JC. The Multidimensional Fatigue Inventory (MFI) psychometric qualities of an instrument to assess fatigue. J Psychosom Res. 1995;39:315-325.

14. Irvine EJ, Zhou Q, Thompson AK. The Short Inflammatory Bowel Disease Questionnaire: a quality of life instrument for community physicians managing inflammatory bowel disease. CCRPT Investigators. Canadian Crohn's Relapse Prevention Trial. Am J Gastroenterol. 1996;91:1571-1578.

15. Bennebroek Evertsz' F, Nieuwkerk PT, Stokkers PCF, et al. The patient simple clinical colitis activity index (P-SCCAI) can detect ulcerative colitis (UC) disease activity in remission: a comparison of the P-SCCAI with clinician-based SCCAI and biological markers. J Crohns Colitis. 2013;7:890-900.

16. Bennebroek Evertsz' F, Hoeks CCMQ, Nieuwkerk PT, et al. Development of the patient Harvey Bradshaw index and a comparison with a clinician-based Harvey Bradshaw index assessment of Crohn's disease activity. J Clin Gastroenterol. 2013;47:850-856.

17. Tamminga SJ, de Jong M, Frings-Dresen MHW, de Boer AGEM. The Quality of Working Life Questionnaire for Cancer Survivors: sufficient responsiveness for use as a patient-reported outcome measurement. Eur J Cancer Care (Engl). 2018;27:e12910.

18. Van Laar D, Edwards JA, Easton S. The work-related quality of life scale for healthcare workers. J Adv Nurs. 2007;60:325-333.

19. de Jong M, Tamminga SJ, de Boer AGEM, Frings-Dresen MHW. Quality of working life of cancer survivors: development of a cancer-specific questionnaire. J Cancer Surviv. 2016;10:394-405.

20. De Boer AGEM, Bennebroek Evertsz' F, Stokkers PC, et al. Employment status, difficulties at work and quality of life in inflammatory bowel disease patients. Eur J Gastroenterol Hepatol. 2016;28:1130-1136.

21. de Jong M, Tamminga SJ, Frings-Dresen MHW, de Boer AGEM. Quality of Working Life of cancer survivors: associations with health- and work-related variables. Support Care Cancer. 2017;25:1475-1484.

22. Le Berre C, Peyrin-Biroulet L, Buisson A, et al. Impact of inflammatory bowel diseases on working life: a French nationwide survey. Dig Liver Dis. 2019;51:961-966.

23. Borren NZ, van der Woude CJ, Ananthakrishnan AN. Fatigue in IBD: epidemiology, pathophysiology and management. Nat Rev Gastroenterol Hepatol. 2019;16:247-259.

24. van Andel EM, Koopmann BDM, Crouwel F, et al. Systematic review of development and content validity of patient-reported outcome measures in Inflammatory Bowel Disease: do we measure what we measure? J Crohns Colitis. 2020; https://doi. org/10.1093/ecco-jcc/jjaa057. 
25. Jones J, Loftus EV, Panaccione R, et al. Relationships between disease activity and serum and fecal biomarkers in patients with Crohn's disease. Clin Gastroenterol Hepatol. 2008;6:1218-1224.

26. Cellier C, Sahmoud T, Froguel E, et al. Correlations between clinical activity, endoscopic severity, and biological parameters in colonic or ileocolonic Crohn's disease. A prospective multicentre study of 121 cases. The Groupe d'Etudes Thérapeutiques des Affections Inflammatoires Digestives. Gut. 1994;35:231-235.
Publisher's Note Springer Nature remains neutral with regard to jurisdictional claims in published maps and institutional affiliations. 